FORMATION Formation emploi

Revue française de sciences sociales

138 | Avril-Juin 2017

La professionnalisation dans l'enseignement supérieur : formes et effets variés

\title{
Edito : Quand la professionnalisation ne se joue (pas) que dans les amphis
}

Jean-Frédéric Vergnies

\section{(2) OpenEdition}

Journals

Édition électronique

URL : http://journals.openedition.org/formationemploi/5056

DOI : 10.4000/formationemploi.5056

ISSN : 2107-0946

Éditeur

La Documentation française

Édition imprimée

Date de publication : 17 juillet 2017

Pagination : $1-2$

ISSN : 0759-6340

Référence électronique

Jean-Frédéric Vergnies, «Edito : Quand la professionnalisation ne se joue (pas) que dans les amphis », Formation emploi [En ligne], 138 | Avril-Juin 2017, mis en ligne le 10 juillet 2017, consulté le 30 octobre 2020. URL : http://journals.openedition.org/formationemploi/5056 ; DOI : https://doi.org/10.4000/ formationemploi.5056

(c) Tous droits réservés 


\section{Quand la professionnalisation ne se joue (pas) que dans les amphis}

Jean-Frédéric Vergnies

Rédacteur en chef

Avec les directives européennes et les récentes lois ministérielles, la professionnalisation est affirmée comme une mission importante de l'enseignement supérieur. Derrière une apparente évidence, la professionnalisation recèle de multiples formes.

Qu'en est-il du rôle de l'injonction européenne à la professionnalisation ? Les comparaisons entre la France et la République tchèque et, d'autre part, la France et l'Italie, menées respectivement par Josef Kavka et Ruggero Iori, révèlent de fortes disparités en la matière. Elles montrent l'importance des orientations différenciées des logiques institutionnelles et du corps enseignant.

Au niveau individuel, Catherine Béduwé et Virginie Mora montrent la diversité des profils de professionnalité des étudiants. Au-delà du diplôme de fin d'études, cette diversité résulte de l'accumulation différenciée des compétences et des signaux.

Poursuivre un même diplôme, en formation classique ou en alternance, modifie parfois, mais pas toujours, la professionnalité des étudiants, d'après Nathalie Beaupère, Xavier Collet et Sabina Issehnane. Selon les spécialités, le segment du marché de l'emploi visé, et aussi les modes de sélection à l'entrée, le passage par l'alternance améliore souvent les chances d'accéder à un emploi à durée indéterminée, mais en même temps, il peut diminuer la probabilité d'accéder à un emploi de cadre.

Approfondissant la dynamique d'offre des formations en alternance, Arnaud Pierrel souligne que le développement des formations en apprentissage dépend largement du fonctionnement, très divers, des établissements et de leur contexte concurrentiel local.

De manière similaire, s'agissant de la place limitée de la formation continue à l'université, Isabelle Borras et Nathalie Bosse montrent le rôle prépondérant des logiques internes au système éducatif. En comparant la France et le Québec, Pierre Doray et Christelle Manifet 
précisent ces logiques et leurs mécanismes, en soulignant l'importance des dynamiques sociétales. S'intéressant, in fine, aux pratiques des enseignants, ici dans le cas emblématique du tutorat des étudiants en IUT ${ }^{1}$, Stéphanie Tralongo rappelle que la professionnalisation constitue un défi pour nombre d'enseignants.

En postface, Vincent Carpentier, mobilisant à la fois une approche économique, historique et comparative, souligne la forte influence des structures de financement sur la mission de professionnalisation de l'enseignement supérieur.

Ainsi, à nouveau ${ }^{2}$, ce dossier rappelle la nécessité, dans l'analyse, de l'hybridation des logiques et des niveaux. Les formes de la professionnalisation relèvent, en partie, des institutions européennes, nationales, et des établissements avec leurs acteurs, mais aussi des contextes locaux éducatifs ou économiques, ou encore des dynamiques individuelles et des processus de socialisation.

Bonne lecture.

1 Instituts universitaires de technologie.

2 Voir Formation Emploi, n 117, "Enseignement supérieur : les défis de la professionnalisation ", janvier-mars 2012 et $\mathrm{n}^{\circ} 132$, "Enseignement supérieur et mondes économiques : de nouveaux éclairages ", octobre-décembre 2015. 